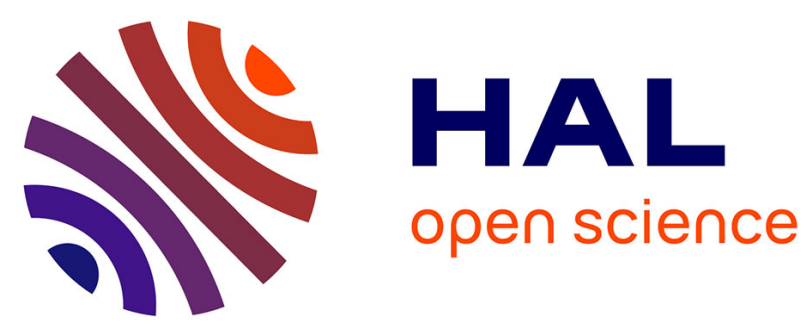

\title{
A method based on Monte Carlo simulations and voxelized anatomical atlases to evaluate and correct uncertainties on radiotracer accumulation quantitation in beta microprobe studies in the rat brain
}

Frederic Pain, Marc Dhenain, Hirac Gurden, Anne-Lise Routier, Françoise Lefebvre, Roland Mastrippolito, Philippe Laniece

\section{To cite this version:}

Frederic Pain, Marc Dhenain, Hirac Gurden, Anne-Lise Routier, Françoise Lefebvre, et al.. A method based on Monte Carlo simulations and voxelized anatomical atlases to evaluate and correct uncertainties on radiotracer accumulation quantitation in beta microprobe studies in the rat brain. Physics in Medicine and Biology, 2008, 53 (19), pp.5385 - 5404. 10.1088/0031-9155/53/19/008 . hal-01694187

\author{
HAL Id: hal-01694187 \\ https://hal.science/hal-01694187
}

Submitted on 31 Jan 2018

HAL is a multi-disciplinary open access archive for the deposit and dissemination of scientific research documents, whether they are published or not. The documents may come from teaching and research institutions in France or abroad, or from public or private research centers.
L'archive ouverte pluridisciplinaire HAL, est destinée au dépôt et à la diffusion de documents scientifiques de niveau recherche, publiés ou non, émanant des établissements d'enseignement et de recherche français ou étrangers, des laboratoires publics ou privés. 
A method based on Monte Carlo simulations and voxelized anatomical atlases to evaluate and correct uncertainties on radiotracer accumulation quantitation in beta microprobe studies in the rat brain

This article has been downloaded from IOPscience. Please scroll down to see the full text article. 2008 Phys. Med. Biol. 535385

(http://iopscience.iop.org/0031-9155/53/19/008)

View the table of contents for this issue, or go to the journal homepage for more

Download details:

IP Address: 129.175.97.14

The article was downloaded on 13/09/2010 at 15:17

Please note that terms and conditions apply. 


\title{
A method based on Monte Carlo simulations and voxelized anatomical atlases to evaluate and correct uncertainties on radiotracer accumulation quantitation in beta microprobe studies in the rat brain
}

\author{
F Pain ${ }^{1}$, M Dhenain ${ }^{2,3}$, H Gurden ${ }^{1}$, A L Routier ${ }^{1}$, F Lefebvre ${ }^{1}$, \\ R Mastrippolito ${ }^{1}$ and $P$ Lanièce $^{1}$ \\ ${ }^{1}$ UMR8165 Imagerie et Modélisation en Cancérologie et Neurobiologie, \\ Universités Paris 11/Paris 7, Campus d'Orsay Bat 104/440 91406 Orsay Cedex, France \\ ${ }^{2}$ Z350 INSERM, Institut Curie, Campus d'Orsay Bat 11291405 Orsay Cedex, France
}

Received 4 December 2007, in final form 11 June 2008

Published 2 September 2008

Online at stacks.iop.org/PMB/53/5385

\begin{abstract}
The $\beta$-microprobe is a simple and versatile technique complementary to small animal positron emission tomography (PET). It relies on local measurements of the concentration of positron-labeled molecules. So far, it has been successfully used in anesthetized rats for pharmacokinetics experiments and for the study of brain energetic metabolism. However, the ability of the technique to provide accurate quantitative measurements using ${ }^{18} \mathrm{~F},{ }^{11} \mathrm{C}$ and ${ }^{15} \mathrm{O}$ tracers is likely to suffer from the contribution of $511 \mathrm{keV}$ gamma rays background to the signal and from the contribution of positrons from brain loci surrounding the locus of interest. The aim of the present paper is to provide a method of evaluating several parameters, which are supposed to affect the quantification of recordings performed in vivo with this methodology. We have developed realistic voxelized phantoms of the rat whole body and brain, and used them as input geometries for Monte Carlo simulations of previous $\beta$-microprobe reports. In the context of realistic experiments (binding of ${ }^{11} \mathrm{C}$-Raclopride to D2 dopaminergic receptors in the striatum; local glucose metabolic rate measurement with ${ }^{18} \mathrm{~F}$-FDG and $\mathrm{H}_{2} \mathrm{O}^{15}$ blood flow measurements in the somatosensory cortex), we have calculated the detection efficiencies and corresponding contribution of $511 \mathrm{keV}$ gammas from peripheral organs accumulation. We confirmed that the $511 \mathrm{keV}$ gammas background does not impair quantification. To evaluate the contribution of positrons from adjacent structures, we have developed $\beta$-Assistant, a program based on a rat brain voxelized atlas and matrices of local detection efficiencies calculated by Monte Carlo simulations for several probe geometries. This program was used to
\end{abstract}

3 Presently URA 2210 Molecular Imaging Research Center 91406 Orsay, France. 
calculate the 'apparent sensitivity' of the probe for each brain structure included in the detection volume. For a given localization of a probe within the brain, this allows us to quantify the different sources of beta signal. Finally, since stereotaxic accuracy is crucial for quantification in most microprobe studies, the influence of stereotaxic positioning error was studied for several realistic experiments in favorable and unfavorable experimental situations (binding of ${ }^{11} \mathrm{C}$-Raclopride to D2 dopaminergic receptors in the striatum; binding of ${ }^{18} \mathrm{~F}$ MPPF to 5HT1A receptors in the dorsal raphe nucleus).

(Some figures in this article are in colour only in the electronic version)

\section{Introduction}

Rodent models are used in most areas of molecular biology, toxicology and drug discovery research to study physiopathogenic mechanisms, and test drug effects. To explore these models in vivo, several imaging techniques such as magnetic resonance imaging (MRI) or positron emission tomography (PET) have been adapted to the temporal and spatial constraints of small animals studies. In this context, the $\beta$-microprobe was developed in our lab a few years ago as a simple and efficient technique. The microprobe technique is complementary to small-animal PET scanners when only local time activity curve measurements are required. The technique relies on the detection with a photomultiplier (PMT) of light pulses generated by positron interactions in the probe radiosensitive tip (plastic scintillating fiber), which is fused to a clear fiber light guide (Pain et al 2000, 2002a). The volume surrounding the probe, where the radioactivity is counted, depends on the labeling isotope. It is limited to a few microliters by the physical range of positrons within biological tissues (Levin and Hoffman 1999, Pain et al 2000, Desbrée et al 2004). Since the probe is implanted close to the biological tissues of interest, the technique offers a high sensitivity and, consequently, a high temporal resolution (1 s or less). The $\beta$-microprobe has been successfully used for several sets of experiments: pharmacokinetics studies in the rat brain using ${ }^{11} \mathrm{C}$-labeled D2 dopaminergic receptor tracers (Zimmer et al 2002a, Ginovart et al 2004, Mauger et al 2005, Vasdev et al 2006, Galineau et al 2006); ${ }^{18} \mathrm{~F}-\mathrm{MPPF}$, a 5HT1A serotoninergic receptor tracer (Zimmer et al 2002b, Rbah et al 2003, Riad et al 2004, Zimmer et al 2004) and neuro-energetics studies of rat brain metabolism and blood flow with ${ }^{18}$ F-FDG (Pain et al 2002b, Millet et al 2004) and ${ }^{15} \mathrm{O}$-water (Weber et al 2003). In addition, it was evaluated as a method of avoiding repeated blood sampling for the determination of arterial input function for PET tracer experiments in rodents (Pain et al 2004). Finally, multimodal studies with the probe were performed using either its versatility to achieve the combination to other invasive techniques such as micro-dialysis (Zimmer et al 2002b) or its insensitivity to high magnetic fields for simultaneous recording with MRI (Desbrée et al 2004, 2007).

Despite the successful and repeated use of the $\beta$-microprobe, we are still concerned with its capacity to provide quantification of PET tracers when we carefully check reported data. The first studies carried out with the $\beta$-microprobe provided relative measurements with the increase or the decrease of a tracer-specific binding under pharmacological challenges (Zimmer et al 2002b, 2002a); additional reports have provided quantitative parameters such as kinetic constants of tracer association to the receptor (Ginovart et al 2004, Mauger et al 2005), local cerebral glucose metabolism (Pain et al 2002b, Millet et al 2004) or cerebral blood flow (Weber et al 2003). Interestingly, several studies pointed out systematic underestimation of 
tracer concentrations in comparison to ex vivo controls (Zimmer et al 2002b, Weber et al 2003, Ginovart et al 2004). To clarify this issue, we have studied the influence on quantitation of the count rate normalization to $\mathrm{kBq} \mathrm{ml}^{-1}$ in $\beta$-microprobe studies. This normalization is performed under the assumption that the whole detection volume is filled with homogeneously labeled brain tissues from the structure of interest. However, an effect similar to partial volume effects, which affect PET images of structures whose dimensions are smaller than twice the detector spatial resolution (Hoffman et al 1979), may occur and could explain the radioactivity concentration underestimation. For an implanted radiosensitive probe, a comparable effect will happen if the volume in which radioactivity is counted contains a hot spot surrounded by tissues where only non-specific binding of the tracer occurs. A quantitative evaluation of this error and a correction method for $\beta$-microprobe studies are still lacking in the literature leading us to propose in the present paper a new method based on Monte Carlo simulations using voxelized input geometries of the rat whole body and brain. Besides 'partial volume' effects, the accuracy of stereotaxic positioning of the probe is crucial for quantification of $\beta$-microprobe studies. Here, we carefully examine these parameters on the basis of previously carried out neurophysiological experiments in rat, and bring new solutions to solve the discrepancy between reports using the probe and ex vivo results.

\section{Material and methods}

\subsection{The $\beta$-microprobe technique: physical origin of the recorded signal}

A typical experiment is carried out as follows. First, after anesthesia, stereotaxic surgery is performed using a rat brain atlas to implant the probe at the desired brain location. Second, the radiotracer labeled with positron emitters $\left({ }^{18} \mathrm{~F},{ }^{11} \mathrm{C}\right.$ or $\left.{ }^{15} \mathrm{O}\right)$ is injected intravenously. Third, the count rate is recorded and normalized to obtain the time activity curve in $\mathrm{kBq} \mathrm{ml}^{-1}$ versus time. The normalization factor was defined as the probe sensitivity (in counts $\mathrm{kBq}^{-1} \mathrm{ml}^{-1}$ ) (Pain et al 2002a) and is a key factor for the ability of the probe to perform quantitative measurements. Before each experiment, it is measured after immersion of the probe in a homogenous radioactive solution with a known concentration. The sensitivity is then derived from the recorded count rate and is used to obtain the time activity curves from the count rate recorded in vivo. In most experimental schemes, the signal detected by the $\beta$-microprobe may come from several sources: (i) positrons from the brain loci of interest, (ii) the positron background signal from adjacent tissues included in the detection volume, (iii) background contribution from $511 \mathrm{keV}$ gammas generated by positrons annihilation, (iv) dark noise of the PMT and (v) Cerenkov radiation in the fiber. The last two contributions have been shown to be negligible using $\beta$-microprobe systems (Pain et al 2000, 2002a, Weber et al 2003). To be able to derive the absolute radioactivity concentration from the detected count rate, it is necessary to quantify each contribution to the overall signal.

\subsection{MRI-based phantom of a whole rat body}

MRI was used to create a whole body rat phantom. A 10 weeks old, 284 g, Sprague Dawley rat was sacrificed by intraperitoneal injection of pentobarbital $\left(2 \mathrm{ml}\right.$ of Dolethal ${ }^{\circledR}$ (Vétoquinol, France), i.e. $0.36 \mathrm{~g}$ of pentobarbital). The rat was fixed in $10 \%$ buffered formalin for seven days before MR imaging on a 4.7 T Bruker Biospec 47/30 system. The spectrometer was equipped with a $12 \mathrm{~cm}$ diameter gradient system $\left(200 \mathrm{mT} \mathrm{m}^{-1}\right)$ and a birdcage probe (Bruker $\mathrm{GmbH}$ ) that was used for signal transmission and reception. Three-dimensional fast spin-echo (RARE) images were recorded with an isotropic resolution of $468.75 \mu \mathrm{m}$ (TR $=2500 \mathrm{~ms}$, 

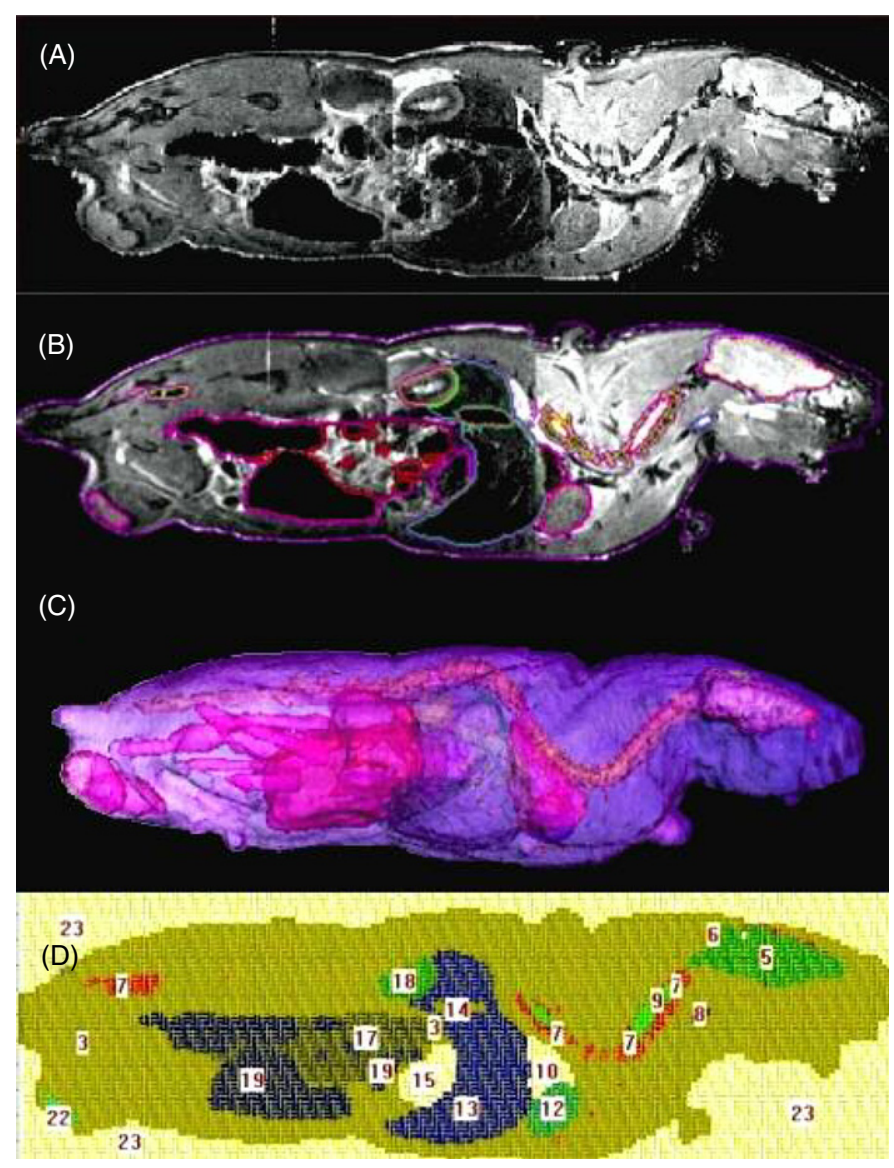

Figure 1. Processing of data from initial MRI images to voxelized Monte Carlo lattice geometry. (A) High-resolution anatomic MR images acquired at 4.7 T. (B) Segmented MR Images. (C) 3D surface rendering. (D) Monte Carlo voxelized input geometry.

$\mathrm{TE}=7 \mathrm{~ms}$, weighted $\mathrm{TE}=52.8 \mathrm{~ms}, \mathrm{RARE}$ factor $=16, \mathrm{NA}=1$, field of view $=12 \times 6 \times$ $6(\mathrm{~cm})$ and matrix $=256 \times 128 \times 128)$. To scan the whole rat body, the rat was manually translated between each acquisition along its anteroposterior axe while its position remained unchanged regarding its dorsoventral and lateral axes. This allowed us to record three overlapping matrices that included the whole rat. Using Amira 3.1 (Mercury Computer Systems, Inc. TGS Unit, Villebon, France), cropping and rigid transformation were applied to each matrix to superimpose the overlapping regions. The three sets of data were then fused resulting in a $138 \times 138 \times 404$ matrix. The main organs susceptible to accumulate radiotracers (brain, eyes, skull, thyroid, heart, lungs, liver, spleen, stomach, large intestine, small intestine, kidneys, bladder, testis, spine, femur, bone marrow and vena cava) were manually segmented. Figure 1 presents the steps followed to build the digital whole body phantom from MRI images to Monte Carlo input file, and table 1 summarizes the volume of the segmented structures.

\subsection{Rat brain phantom construction}

The voxelized rat brain phantom is based on Paxinos and Watson's rat brain atlas in stereotaxic coordinates (Paxinos and Watson 1998), which describes in 78 coronal slices the brain 
Table 1. Whole-body phantom characteristics (male Sprague Dawley rat of $284 \mathrm{~g}$, voxel size 0.938 $\times 0.938 \times 0.938 \mathrm{~mm}^{3}$ )

\begin{tabular}{lrc}
\hline Organ & Number of voxels & Volume $(\mathrm{ml})$ \\
\hline Brain & 2955 & 2.44 \\
Eyes & 37 & 0.03 \\
Skull & 574 & 0.47 \\
Thyroid & 194 & 0.02 \\
Heart & 1113 & 0.91 \\
Lungs & 3610 & 2.98 \\
Liver & 20204 & 16.67 \\
Spleen & 532 & 0.44 \\
Stomach & 4282 & 3.53 \\
Large intestine & 10657 & 8.79 \\
Small intestine & 12971 & 10.70 \\
Kidneys & 1527 & 1.26 \\
Bladder & 65 & 0.054 \\
Testis & 2515 & 2.08 \\
Spine & 3016 & 2.48 \\
Femur & 2237 & 1.85 \\
Bone marrow & 975 & 0.80 \\
Posterior vena cava & 369 & 0.30 \\
\hline
\end{tabular}

structure delineations for a male Wistar rat with an average weight of $290 \pm 20 \mathrm{~g}$. Using an image analysis software (Amira 3.1), these digital slices have been manually segmented into 16 regions of interest, including the main dopaminergic and serotoninergic brain loci and structures such as the striatum, the globus pallidus, the nucleus accumbens, the substantia nigra, the dorsal raphe nucleus, the hippocampus, the ventricles, the aqueduct and the cerebellum. Since the initial slices from Paxinos and Watson atlas are not equidistant, linear $3 \mathrm{D}$ interpolation has been carried out to produce 107 coronal-segmented slices each separated by $200 \mu \mathrm{m}$. The final phantom consists of a $54 \times 78 \times 107$ matrix composed of $200 \mu \mathrm{m}$ side cubic voxels. Table 2 gives the volume of the segmented structures.

\subsection{Monte Carlo simulation of the 511 keV gamma background}

The rat whole body phantom and rat brain matrices were processed with the SCMS software (Yoriyaz et al 2001) to convert them into lattice geometry input files for MCNP-4C2, a Monte Carlo particle interaction simulation code (Briefmeister 2000). To reduce the computing time of the Monte Carlo simulations, the whole body phantom was downsampled to produce a $64 \times 64 \times 202$ matrix composed of $938 \mu \mathrm{m}$ cubic voxels. For each peripheral organ, Monte Carlo simulations were carried out to evaluate the contribution to the total recorded counts of $511 \mathrm{keV}$ gammas from the considered organ. The density and atomic composition of lungs, brain, bones and soft tissues were set according to the National Institute of Standards and Technology (NIST) data (Berger et al 1999). Given $\vec{r}$ the probe position, $S_{i}^{\gamma}(\vec{r}, t)$ the contribution of organ $i$ to the gamma signal at time $t$, then the total signal due to gamma interaction in the probe at time $t$ is

$$
S^{\gamma}(\vec{r}, t)=\sum_{i} S_{i}^{\gamma}(\vec{r}, t)
$$

In a voxelized geometry (organ $i$ is composed of $N_{i}$ voxels), we define for each voxel $j$, the local gamma detection efficiency $\varepsilon_{j}^{\gamma}(\vec{r})$ (which takes into account both the geometrical 
Table 2. Rat brain phantom characteristics (male Wistar rat $290 \mathrm{~g}$ from Paxinos et al (1985), voxel size $\left.0.2 \times 0.2 \times 0.2 \mathrm{~mm}^{3}\right)$.

\begin{tabular}{lrc}
\hline Brain structure & Number of voxels & Volume $(\mu \mathrm{l})$ \\
\hline Cortex and other brain tissues & 162534 & 1300.3 \\
Corpus callosum & 6673 & 53.4 \\
Striatum & 11468 & 91.7 \\
Globus Pallidus & 1292 & 10.1 \\
Lateral ventricle & 1252 & 10.0 \\
Interna Capsula & 1905 & 15.2 \\
Hippocampus & 13553 & 108.4 \\
Olfactory bulb (truncated) & 7739 & 61.9 \\
Olfactory ventricle & 17 & 0.1 \\
Nucleus Accumbens & 1260 & 10.1 \\
Subtantia Nigra & 852 & 6.8 \\
Colliculus & 2491 & 19.9 \\
Aqueduct & 95 & 0.8 \\
Dorsal raphe nucleus & 202 & 1.6 \\
Cerebellum & 29287 & 237.3 \\
\hline
\end{tabular}

efficiency and the attenuation of gammas) and the local gamma radioactivity concentration $C_{j}^{\gamma}(t)$. If $V_{\text {vox }}$ is the volume of each voxel, $S_{i}^{\gamma}(\vec{r}, t)$ is rewritten as

$$
S_{i}^{\gamma}(\vec{r}, t)=V_{\text {vox }} \sum_{j \in \text { organ } i} \varepsilon_{j}^{\gamma}(\vec{r}) C_{j}^{\gamma}(t) .
$$

If we assume in organ $i$ a homogeneous concentration of gamma activity $C_{i}^{\gamma}(t)$, and define for each organ $i$, the mean gamma detection efficiency, $E_{i}^{\gamma}(\vec{r})=\frac{1}{N_{i}} \sum_{j \in \text { organ } i} \varepsilon_{j}^{\gamma}(\vec{r})$, then equation (2) simplifies to

$$
S_{i}^{\gamma}(\vec{r}, t)=V_{\mathrm{vox}} N_{i} E_{i}^{\gamma}(\vec{r}) C_{i}^{\gamma}(t)=V_{i} E_{i}^{\gamma}(\vec{r}) C_{i}^{\gamma}(t),
$$

where $V_{i}$ is the total volume of organ $i$.

For organs outside the brain, the solid angle covered by a $\beta$-probe implanted in the rat brain is very small, and is almost insensitive to the probe location within the brain. Therefore, the detection efficiency for gammas emitted from remote organs is approximately the same, wherever the probe is implanted in the brain. Equation (3) finally is rewritten as

$$
S_{i}^{\gamma}(t)=V_{i} E_{i}^{\gamma} C_{i}^{\gamma}(t) .
$$

Monte Carlo simulations using the whole body digital phantom were carried out to evaluate the mean gamma detection efficiencies $E_{i}^{\gamma}$ for a $500 \mu \mathrm{m}$ diameter probe with a $1 \mathrm{~mm}$ long scintillating tip implanted in the rat striatum and cerebellum at Ginovart et al (2004) stereotaxic coordinates. The gamma background contribution from each organ was calculated using equation (3). ${ }^{18} \mathrm{~F}-\mathrm{FDG}$ biodistribution data were taken from the studies in rats (Kuge et al 1997, van Waarde et al 2004). ${ }^{11} \mathrm{C}$-Raclopride biodistribution values in striatum, brain and Harderian glands were taken from the study of Hume et al (1996). For organs other than the brain, we have used recently published biodistribution values in humans (Slifstein et al 2006). Assuming that ${ }^{11} \mathrm{C}$-Racloppride distribution is similar in human and rat, these values were downscaled to obtain estimates in rat. In humans, the highest accumulation of ${ }^{11} \mathrm{C}$-Raclopride occurs in gallbladder. However, rats do not have a gallbladder. Since the functionality of gallbladder is to concentrate the bile produced by the liver, we have considered the liver to 
be the organ with highest ${ }^{11} \mathrm{C}$-Raclopride in rat. For each organ the simulated concentration corresponds to the peak of tracer accumulation after injection.

For the brain, we have considered a homogeneous tracer accumulation with a concentration similar to that in specific tracer accumulation area. This approach is obviously not realistic, but allows us to estimate the upper level of $511 \mathrm{keV}$ gamma noise contribution to the beta probe signal. Overall, we have always chosen the most unfavorable scheme in terms of gamma noise so that the $511 \mathrm{keV}$ gamma contributions given in table 4 represent the upper level estimation of $511 \mathrm{keV}$ background noise. For pharmacokinetics experiments in the brain, two microprobes are usually implanted: one in the region of interest where specific and non-specific binding occurs and another one in the region of non-specific binding, which is most often the cerebellum. The cerebellum signal is subsequently used to subtract the nonspecific signal from the signal recorded in the region of interest. The underlying assumption is that non-specific signals (including non-specific binding but also $511 \mathrm{kev}$ gamma noise) are the same for both probes. For peripheral organs, the solid angles covered by both probes are identical, which is no longer true for $511 \mathrm{keV}$ sources close to the brain (Harderians glands) or within the brain. To deal with this issue in the case of ${ }^{18} \mathrm{~F}-\mathrm{FDG}$ accumulation and ${ }^{11} \mathrm{C}$-Raclopride binding, we have simulated, for probes implanted in the striatum and in the cerebellum, the following $511 \mathrm{keV}$ contributions: (i) contribution of $511 \mathrm{keV}$ gammas from both striata, and (ii) contribution of $511 \mathrm{keV}$ gammas from Harderian glands.

\subsection{Quantification of the local $\beta$ radioactivity concentration using $\beta$-Assistant}

Using similar definitions and assumptions as for the calculation of the total gamma signal in equation (3), the total positron signal, $S^{\beta}(\vec{r}, t)$, resulting from positrons emitted within the detection volume is

$$
S_{i}^{\beta}(\vec{r}, t)=V_{i} E_{i}^{\beta}(\vec{r}) C_{i}^{\beta}(t),
$$

where $V_{\mathrm{i}}$ is the volume of tissues from brain structure $i$ included in the detection volume for a probe position $\vec{r}$. For positrons, the recorded signals depend on the probe position within the brain, and the assumption leading from equations (3) to (4) is no longer valid.

To quantify and separate the contribution to the signal of positrons from the different brain structures included in the detection volume, we have implemented a strategy based on the superimposition of local detection efficiencies 3D matrix into the voxelized brain phantom. This has led to the development of a Matlab interface called $\beta$-Assistant (figure 2).

Local detection efficiencies matrices were calculated via Monte Carlo simulations of different microprobes geometry surrounded by brain tissues homogeneously labeled with ${ }^{18} \mathrm{~F}$, ${ }^{11} \mathrm{C}$ or ${ }^{15} \mathrm{O}$ tracers. To maintain calculation times within reasonable boundaries, the local detection efficiency matrices were calculated in volumes surrounding the probe that account for $99 \%$ of the recorded beta signal (for details, see Desbrée et al (2004)). These volumes, the associated mean detection efficiency and the theoretical sensitivity are summarized in table 3 for the different probes used in the considered studies.

$\beta$-Assistant was used to review quantification issues from previously carried out neurophysiological experiments with ${ }^{18} \mathrm{~F}-\mathrm{FDG}$ in the striatum and cortex (Pain et al 2002b, Millet et al 2004) ${ }^{11} \mathrm{C}$-Raclopride in the striatum (Zimmer et al 2002a, Ginovart et al 2004) and ${ }^{15} \mathrm{O}-\mathrm{H}_{2} \mathrm{O}$ in the barrel cortex (Weber et al 2003). The experimental parameters of these studies (tracer, probe dimensions and stereotaxic coordinates) are listed in table 5 in the following section. For each experiment, given the dimensions of the probe, the isotope used and the stereotaxic coordinates of implantation, the volume of each brain structure included in the detection volume and the corresponding apparent detection sensitivities 


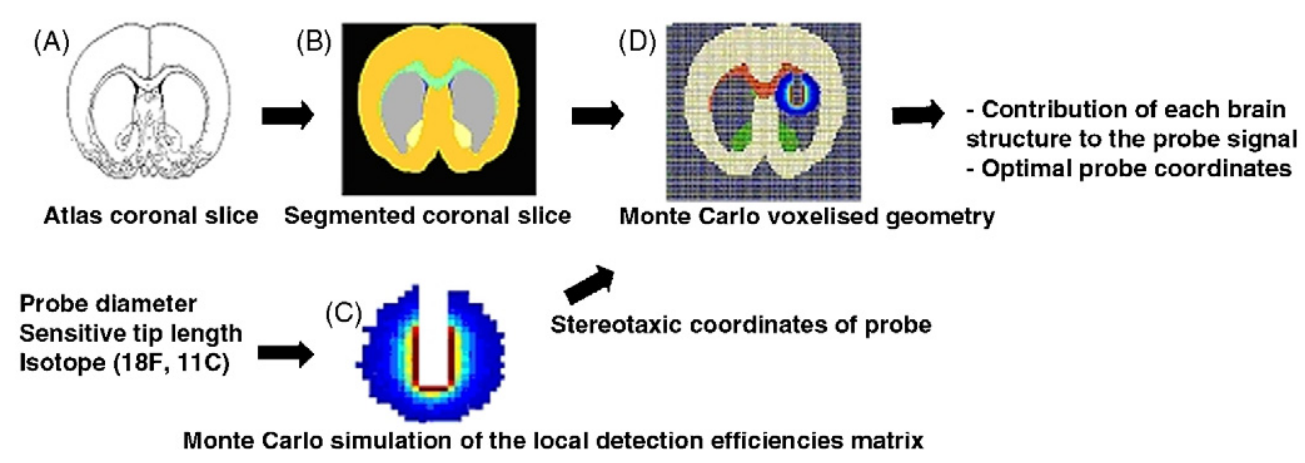

Figure 2. Principle of $\beta$-Assistant. (A) Coronal slice from the Paxinos and Watson rat brain atlas (adapted from Paxinos and Watson 1998). (B) Coronal slice manually segmented. (C) Monte Carlo calculation of local detection efficiencies matrix. (D) 3D Superimposition of the voxelized geometry and the detection efficiencies matrix.

Table 3. The whole detection volume and associated mean detection efficiency for several probe/ tracer combinations.

\begin{tabular}{llllll}
\hline & $\begin{array}{l}\text { Probe } \\
\text { diameter } \\
(\mathrm{mm})\end{array}$ & $\begin{array}{l}\text { Scintillating } \\
\text { tip length } \\
(\mathrm{mm})\end{array}$ & $\begin{array}{l}\text { Whole detection } \\
\text { volume } \\
(\mu \mathrm{l})\end{array}$ & $\begin{array}{l}\text { Mean detection } \\
\text { Tracer } \\
(\%)\end{array}$ & $\begin{array}{l}\text { Theoretical } \\
\text { sensitivity } \\
\text { (Counts/kBq/ml) }\end{array}$ \\
\hline${ }^{18} \mathrm{~F}$ & 0.5 & 1 & 17 & 1.49 & 0.25 \\
${ }^{18} \mathrm{~F}$ & 1 & 1 & 20.7 & 2.7 & 0.56 \\
${ }^{11} \mathrm{C}$ & 0.5 & 1 & 46.6 & 1.1 & 0.51 \\
${ }^{11} \mathrm{C}$ & 1 & 1 & 72.1 & 1.7 & 1.23 \\
${ }^{11} \mathrm{C}$ & 0.5 & 1.5 & 57.7 & 1.37 & 0.79 \\
${ }^{15} \mathrm{O}$ & 0.25 & 0.8 & 190 & 0.15 & 0.29 \\
\hline
\end{tabular}

were calculated. The normalization factors were evaluated to account for the differences between theoretical sensitivities (entire detection volume filled homogeneously with tracer) and apparent sensitivities. In addition, $\beta$-Assistant was used to evaluate the influence of probe placement accuracy on quantification. The positron signal from a brain structure can be calculated for a range of stereotaxic coordinates surrounding an initial stereotaxic coordinates set. This provides with an optimal stereotaxic coordinates set for a particular structure and an estimation of the influence of the probe position accuracy on the measurement. We simulated a pharmacokinetics study with a probe implanted in the center of the striatum, which is an a priori favorable situation since the striatum is a large structure. We also simulated the same experiment but with the supplementary condition that the probe should not penetrate the striatal tissues. Finally, we simulated the unfavorable situation of an implantation close to the dorsal raphe nucleus a small, irregularly shaped serotoninergic brain structure.

\section{Results}

\subsection{Quantification of $511 \mathrm{keV} \mathrm{gamma} \mathrm{background} \mathrm{in}{ }^{18} \mathrm{~F}$-FDG and ${ }^{11} \mathrm{C}$-Raclopride studies}

The contributions of gammas to the $\beta$-microprobe signal are related to the total amount of radioactivity located in each organ. These quantities depend on the biodistribution of the tracer and the volume of the organ. Using biodistribution values in rats for ${ }^{18} \mathrm{~F}$-FDG (Kuge 
Table 4. Total detection efficiency for $511 \mathrm{keV}$ gammas and corresponding contribution to the overall microprobe signal. Biodistribution values are taken from the following references: ${ }^{\mathrm{a}} \mathrm{van}$

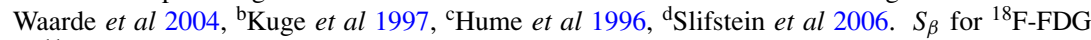
or ${ }^{11} \mathrm{C}$-Raclopride in the striatum were calculated assuming an activity concentration in the whole detection volume similar to the mean biodistribution of the tracer.

\begin{tabular}{|c|c|c|c|c|c|}
\hline \multirow[b]{2}{*}{ Organ } & \multirow{2}{*}{$\begin{array}{l}\text { Calculated total } \\
511 \mathrm{keV} \text { gammas } \\
\text { detection efficiency } \\
\text { for a probe implanted } \\
\text { in the rat striatum } \\
E_{i}^{\gamma}(\vec{r})\left(10^{-4} \%\right)\end{array}$} & \multicolumn{2}{|c|}{${ }^{18} \mathrm{~F}-\mathrm{FDG}$} & \multicolumn{2}{|c|}{${ }^{11} \mathrm{C}$-Raclopride } \\
\hline & & $\begin{array}{l}\text { Mean } \\
\text { biodistribution } \\
\left(\mathrm{kBq} \mathrm{ml}^{-1}\right)\end{array}$ & $\begin{array}{l}\text { Contribution to the } \\
\text { total microprobe } \\
\text { signal } \frac{S_{\gamma}(t)}{S_{\beta}(t)+S_{\gamma}(t)} \\
(\%)\end{array}$ & $\begin{array}{l}\text { Mean } \\
\text { biodistribution } \\
\left(\mathrm{kBq} \mathrm{ml}^{-1}\right)\end{array}$ & $\begin{array}{l}\text { Contribution to the } \\
\text { total microprobe } \\
\text { signal } \frac{S_{\gamma}(t)}{S_{\beta}(t)+S_{\gamma}(t)} \\
(\%)\end{array}$ \\
\hline Brain & $5.500 \pm 0.230$ & $198^{\mathrm{a}}$ & 5.72 & $10^{\mathrm{c}}$ & 0.5 \\
\hline $\begin{array}{l}\text { Eyes } \\
\text { (Harderian glands) }\end{array}$ & $0.350 \pm 0.059$ & $100^{\mathrm{b}}$ & $<0.01$ & $152^{\mathrm{c}}$ & $<\mathbf{0 . 0 1}$ \\
\hline Heart & $0.110 \pm 0.033$ & $796^{\mathrm{a}}$ & 0.22 & $60^{\mathrm{d}}$ & 0.02 \\
\hline Lungs & $0.110 \pm 0.033$ & $157^{\mathrm{a}}$ & 0.14 & $60^{d}$ & 0.06 \\
\hline Liver & $0.080 \pm 0.028$ & $695^{\mathrm{a}}$ & 0.25 & $240^{\mathrm{d}}$ & 0.97 \\
\hline Kidneys & $0.056 \pm 0.022$ & $258^{\mathrm{a}}$ & 0.04 & $60^{d}$ & 0.01 \\
\hline Large intestine & $0.070 \pm 0.026$ & $187^{\mathrm{a}}$ & 0.31 & $30^{\mathrm{d}}$ & 0.06 \\
\hline Small Intestine & $0.01<$ & $150^{\mathrm{a}}$ & 0.04 & $30^{\mathrm{d}}$ & 0.01 \\
\hline Bladder & $0.01<$ & $1227^{\mathrm{a}}$ & $\mathbf{0}$ & $120^{\mathrm{d}}$ & $<0.01$ \\
\hline Total & & & 6.72 & & 1.65 \\
\hline
\end{tabular}

a van Waarde et al 2004.

${ }^{\mathrm{b}}$ Kuge et al 1997.

${ }^{\mathrm{c}}$ Hume et al 1996

et al 1997, van Waarde et al 2004) and for ${ }^{11}$ C-Raclopride in rats (Hume et al 1996) and humans (Slifstein et al 2006), the contribution of gammas from the brain and remote organs to the detected signal was simulated for the most currently used microprobe geometry $(500 \mu \mathrm{m}$ diameter with a $1 \mathrm{~mm}$ long scintillating tip) implanted in the rat striatum. Calculated values for the mean gamma detection efficiencies for each organ $E_{i}^{\gamma}(\vec{r})$ are given in table 4. Harderian glands could not be segmented in the rat whole body phantom, but are known to present high accumulation for both tracers. Therefore, we confounded them with the eyes since Harderian glands are located in the orbital cavity. Comparing values from tables 3 and 4, we can observe that the detection efficiency for gammas is 4-5 orders of magnitude lower than the detection efficiency for positrons. The main source of gamma noise is the brain for ${ }^{18} \mathrm{~F}$-FDG and the brain and liver for ${ }^{11} \mathrm{C}$-Raclopride, even if both isotopes accumulate strongly in other organs. Overall, the total gamma contribution does not exceed $6.7 \%$ and $1.65 \%$ of the probe signal for ${ }^{18}$ F-FDG and ${ }^{11} \mathrm{C}$-Raclopride, respectively.

For a probe implanted in the cerebellum, the contribution of $511 \mathrm{keV}$ gammas from remote organs (e.g., heart, lungs liver and bladder) is the same as for the probe in the striatum, since the solid angles covered by the probes for these structures are almost identical. For sources of $511 \mathrm{keV}$ gammas within the brain (specific or non-specific binding of tracer to brain structures outside the probe detection volume) or the Harderian glands, we have carried out further simulations to evaluate their different contributions to the cerebellum probe. The detection efficiency for $511 \mathrm{keV}$ gammas from both striata is about $10^{-4} \%$ for the cerebellum compared to a detection efficiency of $10^{-3} \%$ for the gammas from the other striatum for the striatum probe. Regarding the Harderian glands, the detection efficiency of the cerebellum probe for $511 \mathrm{keV}$ gammas is about twice lower than the detection efficiency of the striatum probe due to solid angle effects. However, these differences have no influence on the quantification of the beta signal, since the signal resulting from these $511 \mathrm{keV}$ gammas is less than $0.5 \%$ of the specific beta signal. 


\subsection{Quantification and optimization of the positron background signal from adjacent tissues}

The volume of the targeted structure included in the detection volume and the corresponding apparent sensitivity have been calculated for a wide range of representative experimental situations. These experimental parameters and the results of the simulation carried out with $\beta$-Assistant are summarized in table 5 .

3.2.1. Quantification in ${ }^{18} \mathrm{~F}$ studies. We have simulated experiments with ${ }^{18} \mathrm{~F}-\mathrm{FDG}$ in the striatum, in the barrel cortex and the frontal cortex carried out by Pain et al (2002) and Millet et al (2004).

For striatum studies carried out with a $1 \mathrm{~mm}$ diameter probe, the superimposition of the detection volume onto the coronal plane shows that most of the detection volume is apparently entirely enclosed in the striatum (see table 5, figure B). However, the 3D superimposition demonstrates that only $73 \%$ of the total detection volume is included in the striatum, thus leading to a $23 \%$ underestimation of the tracer accumulation.

For the study of ${ }^{18}$ F-FDG accumulation in the barrel cortex, a probe with $1 \mathrm{~mm}$ diameter was used. It was not implanted in the tissues to limit the invasiveness of the technique, but was just positioned on the cortex surface (table 5, figure A). Therefore, a large part of the detection volume is located outside the brain and filled with air. Only $44 \%$ of the detection volume is filled with cortical tissues. The actual tracer accumulation is consequently underestimated by a factor of 2.3. For apparently similar studies carried out in the frontal cortex (Millet et al 2004), this underestimation is much more moderate (13\%). This difference results from two experimental parameters: first the probe was lowered by $2 \mathrm{ml}$ inside the cortex; second the probe used is a smaller diameter probe $(0.5 \mathrm{~mm}$ instead of $1 \mathrm{~mm})$ that leads to a smaller detection volume (see table 5 figure $\mathrm{C}$ ) and minimizes the underestimation effect. For an implantation in the cerebellum that is commonly used in pharmacokinetics studies to account for tracer bound non-specifically to its molecular target, the entire detection volume is filled with cerebellar tissues for either a $1 \mathrm{~mm}$ diameter or a $0.5 \mathrm{~mm}$ diameter probe. Consequently, no underestimation of the non-specific binding occurs with ${ }^{18} \mathrm{~F}$ tracers in the cerebellum.

3.2.2. Quantification in ${ }^{11} \mathrm{C}$ studies. We have simulated two ${ }^{11} \mathrm{C}$-Raclopride binding experiments carried out in the rat striatum (Zimmer et al 2002b, Ginovart et al 2004). Zimmer et al used a probe with $1 \mathrm{~mm}$ diameter to study the competitive binding to D2 dopaminergic receptors under several pharmacological challenges. Simulating an implantation at Zimmer et al stereotaxic coordinates, only $38 \%$ of the detection volume is included in the striatum, and the resulting tracer concentration underestimation is $50 \%$. Ginovart et al have performed similar experiments using other stereotaxic coordinates and a smaller diameter $(0.5 \mathrm{~mm})$ probe to limit invasiveness. Although their study concluded the ability of the technique to monitor efficiently in vivo the influence of pharmacological treatments on tracer occupancy of striatal D2 receptors, it pointed out an overall underestimation close to a factor 2 of the radioactivity concentration compared to ex vivo counting of striatal samples. Simulations show that, with a probe implanted at Ginovart et al stereotaxic coordinates, only $50 \%$ of the detection volume is filled with striatal tissues and consequently the signal is underestimated by $23 \%$. Applying a correction factor derived from the apparent sensitivity to the data does not allow us to correct fully the observed underestimation compared to ex vivo counting. We bring further explanation about this apparent discrepancy in the discussion (see section 3 ).

For either a $1 \mathrm{~mm}$ or a $0.5 \mathrm{~mm}$ diameter probe geometry, the detection volume is entirely included in the cerebellum for ${ }^{11} \mathrm{C}$-labeled tracers. Therefore, the quantification of the nonspecific binding (measured classically from the radioactivity accumulation in the cerebellum) 
Table 5. Proportion of targeted tissues in the detection volume, corresponding apparent sensitivities and correction factors for representative ${ }^{18} \mathrm{~F},{ }^{11} \mathrm{C}$ or ${ }^{15} \mathrm{O}$ microprobe studies. A, B, C, D and E drawings are the superimposition of the probe and detection volume on coronal planes (adapted from Paxinos and Watson 1988)

\begin{tabular}{|c|c|c|c|c|c|c|c|c|c|c|c|c|}
\hline \multirow[b]{2}{*}{ Tracer } & \multirow[b]{2}{*}{ Reference } & \multirow[b]{2}{*}{$\begin{array}{l}\text { Corresponding } \\
\text { drawing }\end{array}$} & \multirow[b]{2}{*}{$\begin{array}{l}\text { Brain } \\
\text { structure }\end{array}$} & \multirow{2}{*}{$\begin{array}{l}\text { Probe } \\
\text { diameter } \\
(\mathrm{mm})\end{array}$} & \multirow{2}{*}{$\begin{array}{l}\text { Tip } \\
\text { length } \\
(\mathrm{mm})\end{array}$} & \multicolumn{3}{|c|}{ Stereotaxic coordinates } & \multirow{2}{*}{$\begin{array}{l}\text { Volume included } \\
\text { in the targeted } \\
\text { brain structure } \\
(\mu 1)\end{array}$} & \multirow{2}{*}{$\begin{array}{l}\text { Percentage } \\
\text { of total } \\
\text { detection } \\
\text { volume }\end{array}$} & \multirow{2}{*}{$\begin{array}{l}\text { Apparent } \\
\text { sensitivity } \\
(\text { cts } / \mathrm{kBq} / \mathrm{ml})\end{array}$} & \multirow{2}{*}{$\begin{array}{l}\text { Correction factor }= \\
\text { theoretical sensitivity } \\
\text { (table } 4 \text { )/apparent } \\
\text { sensitivity }\end{array}$} \\
\hline & & & & & & $\begin{array}{l}\text { AP/Bregma } \\
(\mathrm{mm})\end{array}$ & $\begin{array}{l}\text { ML } \\
(\mathrm{mm})\end{array}$ & $\begin{array}{l}\mathrm{DV} \\
(\mathrm{mm})\end{array}$ & & & & \\
\hline${ }^{18} \mathrm{~F}-\mathrm{FDG}$ & Pain et al (2002b) & A & Barrel cortex & 1.0 & 1.0 & -1.0 & 6.0 & -2.1 & 9.2 & 44 & 0.24 & 2.31 \\
\hline${ }^{18} \mathrm{~F}-\mathrm{FDG}$ & Pain et al (2002b) & B & Striatum & 1.0 & 1.0 & -0.5 & 3.0 & -5.0 & 15.2 & 73 & 0.45 & 1.23 \\
\hline${ }^{18} \mathrm{~F}-\mathrm{FDG}$ & Millet et al (2004) & $\mathrm{C}$ & Frontal cortex & 0.5 & 1.0 & 2.5 & 3.5 & -2.0 & 12.3 & 73 & 0.22 & 1.13 \\
\hline \multirow[t]{2}{*}{${ }^{18} \mathrm{~F}$ tracer } & & & Cerebellum & 0.5 & 1.0 & -11.8 & 0.0 & -3.5 & 17.0 & 100 & 0.25 & 1.00 \\
\hline & & & Cerebellum & 1.0 & 1.0 & -11.8 & 0.0 & -3.5 & 20.7 & 100 & 0.56 & 1.00 \\
\hline${ }^{11} \mathrm{C}$-Raclopride & Zimmer et al (2002a) & & Striatum & 1.0 & 1.0 & 1.0 & 2.5 & -6.0 & 27.1 & 38 & 0.82 & 1.50 \\
\hline${ }^{11} \mathrm{C}$-Raclopride & Ginovart et al (2004) & $\mathrm{D}$ & Striatum & 0.5 & 1.0 & 0.2 & 2.8 & -6.0 & 22.8 & 49 & 0.41 & 1.23 \\
\hline${ }^{11} \mathrm{C}$-Raclopride & Ginovart et al (2004) & & Striatum & 0.5 & 1.5 & 0.2 & 2.8 & -6.0 & 27.5 & 38 & 0.62 & 1.26 \\
\hline \multirow[t]{2}{*}{${ }^{11} \mathrm{C}$ tracer } & & & Cerebellum & 0.5 & 1.0 & -11.8 & 0.0 & -3.5 & 44.8 & 96 & 0.51 & 1.01 \\
\hline & & & Cerebellum & 1.0 & 1.0 & -11.8 & 0.0 & -3.5 & 70.3 & 98 & 1.27 & 0.96 \\
\hline \multirow[t]{2}{*}{${ }^{15} \mathrm{O}-\mathrm{H}_{2} \mathrm{O}$} & Weber et al (2003) & E & Barrel cortex & 0.25 & 0.8 & -2.0 & 6.0 & -1.4 & 71.4 & 38 & 0.17 & 1.66 \\
\hline & & B & & & $\mathrm{C}$ & & & D & & & E & \\
\hline
\end{tabular}


Table 6. Evaluation by the $\beta$-Assistant of the apparent detection efficiencies for implanted probes in a ${ }^{11} \mathrm{C}$-Raclopride binding experiment. Stereotaxic coordinates that define the probe position $\vec{r}$ are taken from Ginovart et al 2004 (striatum probe: DV-6.0, AP-0.2, ML-2.8); note that the whole detection volume for ${ }^{11} \mathrm{C}$ is $46.6 \mu \mathrm{l}$ (sum of the $V_{\mathrm{i}}$ ).

\begin{tabular}{lll}
\hline & \multicolumn{2}{c}{ Striatum probe (1 mm long) } \\
\cline { 2 - 3 } & $\begin{array}{l}V_{i}, \text { volume included } \\
\text { in the detection } \\
\text { volume }(\mu \mathrm{l})\end{array}$ & $\begin{array}{l}E_{i}^{\beta}(\vec{r}), \text { apparent } \\
\text { detection } \\
\text { efficiency }(\%)\end{array}$ \\
\hline Brain structure & $\mathbf{2 2 . 8}$ & $\mathbf{1 . 8 2}$ \\
Corpus callosum & 0.5 & 0.23 \\
Globus Pallidus & 3.8 & 0.96 \\
Nucleus Accumbens & 2.7 & 0.5 \\
Internal Capsula & 1.3 & 0.5 \\
Lateral ventricle & 0.1 & 0.28 \\
Cortex and other tissues & 15.6 & 0.28 \\
\hline
\end{tabular}

is accurate, and does not need to be corrected, which is in agreement with the comparison between microprobe data and cerebellum ex vivo counting in the study of Ginovart et al.

Although striatum is the main source of the signal for the striatum probe in the Ginovart et al study, only $22.8 \mu \mathrm{l}$ of the whole detection volume $(46.6 \mu \mathrm{l})$ is filled with striatal tissues (tables 4 and 5). In addition, in striatal studies, the remaining part of the detection volume is not filled with air like that in cortex studies with ${ }^{18} \mathrm{~F}-\mathrm{FDG}$, but with brain tissues that might contribute significantly to the signal. Therefore, it is crucial for quantification to evaluate positron contributions from surrounding structures. Ex vivo experiments carried out by Ginovart $e$ al showed that the striatum-to-cerebellum ratio in ${ }^{11} \mathrm{C}$-Raclopride radioactivity concentration increases from 2.2 ( 5 min post-injection) to 12.6 (60 min post-injection). The radioactivity concentration in non-striatal tissues included in the detection volume was considered to be similar to that in cerebellum, assuming that, for pharmacological studies, non-specific binding can be evaluated accurately from the cerebellum radioactivity. The contribution to the signal due to positrons emitted from adjacent tissues was calculated using the volume of each surrounding brain structure included in the detection volume, and corresponding apparent sensitivities calculated with $\beta$-Assistant (table 6 and equation (5)). Since specific binding increases through time, this contribution is less than $10 \%$ of the whole beta signal $5 \mathrm{~min}$ post-injection, and less than $2 \% 60 \mathrm{~min}$ post-injection for a $0.5 \mathrm{~mm}$ diameter probe with a $1 \mathrm{~mm}$ long sensitive tip.

3.2.3. Quantification in ${ }^{15} \mathrm{O}$ studies. The detection volume associated with ${ }^{15} \mathrm{O}$ labeled tracer is very large (about $190 \mu \mathrm{l}$ ) due to high maximum energy of the ${ }^{15} \mathrm{O} \beta$-spectrum. This minimizes the spatial resolution since the measured signal comes from a large amount of tissues (Table 5, figure E). However, Weber et al successfully monitored cerebral blood flow changes using a $250 \mu \mathrm{m}$ diameter probe and ${ }^{15} \mathrm{O}$-water (Weber et al 2003). As observed in table 5, only $38 \%$ of the detection volume associated with ${ }^{15} \mathrm{O}$ is filled with cortical tissues in their experiment. Using the theoretical probe sensitivity $\left(0.29 \mathrm{cts} \mathrm{kBq}^{-1} \mathrm{ml}^{-1}\right)$ to normalize the data from counts per seconds to $\mathrm{kBq} \mathrm{ml}^{-1} \mathrm{~s}^{-1}$, the signal is underestimated by $66 \%$. This inaccuracy on quantitation is not a concern when only relative increases or decreases of blood flow are measured following a sensorial stimulation or a pharmacological challenge. However, raw data should be carefully corrected before using compartmental models to obtain quantitative estimation of parameters such as the cerebral blood flow. 


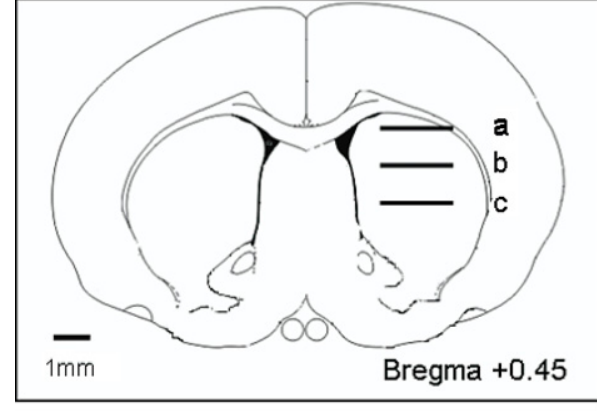

regma +0.45

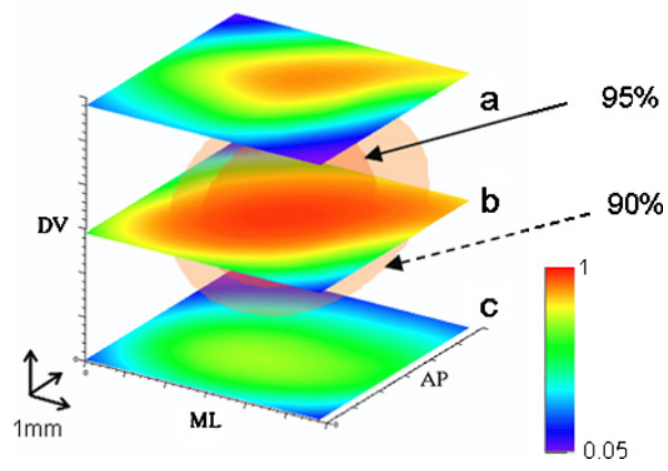

Figure 3. Optimization of stereotaxic coordinates for ${ }^{11} \mathrm{C}$-Raclopride experiments in the rat striatum. A, B and C are planes through the apparent sensitivity matrix. Each pixel of the matrix corresponds to a stereotaxic coordinates set, and its value is the corresponding recorded signal normalized to the signal recorded at the optimal position (DV-4.9 mm, AP-0.4 mm, ML-2.9 mm). For clarity only three dorsoventral planes are shown: (a) $-3.4 \mathrm{~mm}$, (b) $-4.9 \mathrm{~mm}$, (c) $-6.4 \mathrm{~mm}$. $90 \%$ and $95 \%$ apparent sensitivity isosurfaces are also represented, respectively, by a plain and a dotted arrow.

3.2.4. Influence of the accuracy of the probe placement. Overall, the choice of stereotaxic coordinates and the accuracy of the probe placement are parameters likely to influence microprobe measurement. For experiments in the cortex with either ${ }^{18} \mathrm{~F},{ }^{11} \mathrm{C}$ or ${ }^{15} \mathrm{O}$ (Pain et al 2002, Weber et al 2003, Millet et al 2004), the probe positioning results from a trade-off between signal optimization and invasiveness. Consequently, the probe is usually positioned above the cortical structure of interest to minimize tissue damages. For the particular case of experiments of ${ }^{18} \mathrm{~F}-\mathrm{FDG}$ accumulation in the barrel cortex (Pain et al 2002), the effect of stereotaxic accuracy is minimized by the large dimension of the activated area. In fact, due to the rapid spread of activation across the barrel cortex, a relatively large zone is homogeneously activated even when one whisker is deflected (Petersen et al 2007). In addition, autoradiographic controls from our previous experiments (Pain et al 2002) showed that the surface of the activated area corresponding to barrel field (S1BF) is more than $10 \mathrm{~mm}^{2}$ when all whiskers are stimulated simultaneously. Interestingly, this was also shown by ${ }^{18} \mathrm{~F}$ FDG small-animal PET experiments (Kornblum 2000). In these experiments, the positioning of the probe benefits from the visual control that helps in minimizing the error. Taken all together, for experiences in the rat cortex, even a large error in the probe positioning on the cortical surface will result in moderate differences in recorded signals.

For pharmacological experiments with ${ }^{11} \mathrm{C}$-Raclopride in the striatum, the probe tip is located inside the tissues. We have evaluated the optimal probe stereotaxic coordinates and the influence of the placement accuracy on quantification for a $500 \mu \mathrm{m}$ diameter probe with a $1 \mathrm{~mm}$ long sensitive tip. Figure 3 shows slices through dorsoventral planes intersecting the 3D matrix of the signal recorded from striatum normalized to the signal recorded at the optimal coordinates set (DV-4.9, AP-0.4, ML-2.9). For these stereotaxic coordinates, the volume of striatal tissues included in the detection volume is $28.6 \mu \mathrm{l}$ associated with a $0.47 \mathrm{cts}_{\mathrm{kBq}}^{-1}$ $\mathrm{ml}^{-1}$ apparent sensitivity. For the sake of clarity, two isosurfaces corresponding to $90 \%$ and $95 \%$ of the signal recorded at the optimal position are shown. Since the dimensions of the striatum are large, it appears that there is little influence of the possible inaccuracy on the implantation coordinates. Indeed, an imprecision of $800 \mu \mathrm{m}$ in any directions around the optimal position leads to less than $10 \%$ decrease in the apparent sensitivity in striatum. 
Besides these particular experimental situations, which are relatively unaffected by stereotaxic inaccuracy, for most $\beta$-microprobes experiments, the choice of the stereotaxic coordinates and the accuracy of the positioning are critical for the interpretation of the signals. For pharmacokinetics experiments in the striatum with ${ }^{11} \mathrm{C}$-Raclopride, if, to minimize the invasiveness, the striatal tissues should not be damaged by the probe, then the optimal coordinates given by $\beta$-Assistant are DV-5.2 mm, AP-1.9 mm and ML-5.25 mm. For these stereotaxic coordinates, the volume of striatal tissues included in the detection volume is $12.94 \mu \mathrm{l}$ associated with an apparent sensitivity of $0.22 \mathrm{cts} \mathrm{kBq} \mathrm{ml}^{-1}$. For $400 \mu \mathrm{m}, 600 \mu \mathrm{m}$ or $800 \mu \mathrm{m}$ maximum stereotaxic errors on any coordinates the apparent sensitivities ranges are respectively, $0.14-0.30 \mathrm{cts} \mathrm{kBq}^{-1} \mathrm{ml}^{-1}, 0.11-0.34 \mathrm{cts} \mathrm{kBq}^{-1} \mathrm{ml}^{-1}$ and $0.08-0.37 \mathrm{cts} \mathrm{kBq}^{-1}$ $\mathrm{ml}^{-1}$. The upper sensitivities correspond to errors inaccuracy that result in probe positioning in the striatal tissues, whereas the lower sensitivities correspond to probe positioning outside the striatal tissues.

We have studied the particularly unfavorable situation of the measurement of ${ }^{18} \mathrm{~F}-\mathrm{MPPF}$ binding to serotoninergic receptors in the dorsal raphe nucleus (DRN), a small, deep, irregularly shaped brain locus. The optimal coordinates given by $\beta$-Assistant for this structure are DV-6.3 mm, AP-8.5 mm and ML- $0.55 \mathrm{~mm}$ with the condition that the probe does not penetrate

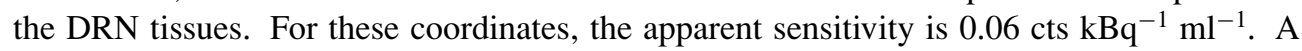
$400 \mu \mathrm{m}$ stereotaxic error in any direction leads to apparent sensitivity values ranging from

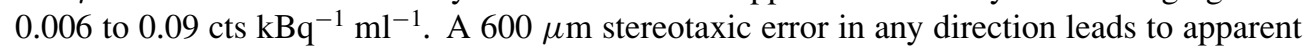
sensitivity values ranging from 0.002 to $0.14 \mathrm{cts} \mathrm{kBq}^{-1} \mathrm{ml}^{-1}$.

\section{Discussion}

In $\beta$-microprobe experiments, the absolute tracer concentration in a targeted structure is derived from the radioactivity count rate measured by the scintillating probe associated with a low dark noise photomultiplier. To convert the count rate (in counts per s) to a local activity concentration (in $\mathrm{Bq} \mathrm{ml}^{-1}$ ), the sensitivity of the probe (in counts per s per $\mathrm{Bq} \mathrm{ml}^{-1}$ ) has to be measured. Then, the derivation of the activity concentration is either straightforward (for large structures) or requires some modeling to take into account the apparent dilution of the radioactivity in the brain structure. Several effects throughout this process can be pointed as potential sources of error for absolute quantification: (i) fluctuation of the dark noise of the PMT, (ii) the Cerenkov signal generated in the fiber, (iii) background contribution from gammas, (iv) background contribution from adjacent $\beta$ signals, (v) error in the probe calibration accuracy and (vi) accuracy of stereotaxic placement of the probe.

\subsection{Dark noise of the PMTs and Cerenkov noise}

The contribution of the PMT dark noise is negligible, since the PMTs used in the $\beta$-microprobe system (Hamamatsu R7400P) were chosen for their particularly low and stable noise (less than five counts per s). Before tracer injection, $\beta$-microprobe electronics should be powered on for at least 10 min to allow high voltage and PMT to heat up and reach a stable dark noise of 2-3 counts per s. Cerenkov noise has been demonstrated experimentally to be negligible in tissues, since violet/blue light is rapidly absorbed by hemoglobin (Pain et al 2002a, Weber et al 2003).

\subsection{The $511 \mathrm{keV}$ gamma rays background}

The detection efficiencies for $511 \mathrm{keV}$ gamma rays do not exceed $10^{-4} \%$ in organs and $10^{-3} \%$ in the brain (table 4). However, since gammas have a high penetrating power in soft tissues, 
remote organs, which accumulate radioactivity can become a source of the background signal. To minimize this contribution, previous theoretical and simulation studies have shown the interest in plastic scintillators compared to inorganic scintillators (Pain et al 2000, 2002a). In the present study, further simulations have been carried out to quantify the contribution of $511 \mathrm{keV}$ gammas in representative neurophysiological experiments in the rat striatum, taking into account the biodistribution of radiotracers $\left({ }^{18} \mathrm{~F}-\mathrm{FDG}\right.$ and ${ }^{11} \mathrm{C}$-Raclopride) and the complex geometry of organs.

For ${ }^{18}$ F-FDG studies, Monte Carlo simulations of the $511 \mathrm{keV}$ gamma rays background show that the total gamma contribution does not exceed $6.72 \%$ of the overall probe signal. Furthermore, this non-negligible value corresponds to the most unfavorable detection situation, i.e., after $60 \mathrm{~min}$ of continuous accumulation of ${ }^{18} \mathrm{~F}-\mathrm{FDG}$ in organs. Indeed, after venous injection ${ }^{18} \mathrm{~F}$-FDG spreads rapidly and accumulates highly in many organs especially in the brain and heart. For ${ }^{11} \mathrm{C}$-Raclopride studies, the $511 \mathrm{keV}$ gamma rays background is due essentially to brain and liver tissues, and is limited to $1.65 \%$ of the overall probe signal. The possible contribution from the eyes and Harderian glands was carefully evaluated for both tracers, since high accumulation of ${ }^{18} \mathrm{~F}-\mathrm{FDG}$ and ${ }^{11} \mathrm{C}$-Raclopride in these glands has been reported (Hume et al 1996, Kuge et al 1997). The contribution of these structures to the signal is negligible (less than $0.01 \%$ of the overall signal) for both tracers, because of the small solid angle covered by the probe and the low detection efficiency of plastic scintillators for gamma rays. For $511 \mathrm{keV}$ sources within the brain (loci with high specific accumulation) or close to the brain (Harderian glands) the simulations have shown that due to solid angle effects, the detection efficiencies for a reference probe implanted in the cerebellum are lower than those of a measurement probe (the striatum probe in our study). However, these differences have no consequences on the quantitation of the beta signal since the resulting contributions to the probe signal are negligible. For pharmacokinetics studies, this validates the use of the cerebellum probe as a reference probe to take into account non-specific binding, provided that the specific molecular targets are actually absent in the cerebellum tissues.

Interestingly, although the calculated values of $E_{i}^{\gamma}(\vec{r})$ given in table 4 correspond to a particular set of stereotaxic coordinates in striatum, they are also valid for any other set of stereotaxic coordinates in the rat brain. Indeed, the solid angle subtended by remote organs is unchanged for any set of stereotaxic coordinates within the brain. Therefore, the particular detection efficiencies for $511 \mathrm{keV}$ gammas calculated in the present study could be generalized for other probe locations to evaluate the gamma background contribution in the brain and other PET tracers.

\subsection{Positron background}

The contribution of positrons emitted in surrounding tissues is negligible for cortical or cerebellum measurements for ${ }^{11} \mathrm{C}$ and ${ }^{18} \mathrm{~F}$ studies. For cortical studies the detection volume is filled either with the cortical tissues or with air from the outside of the brain. For cerebellum studies, the probe technique benefits from the large dimensions of this brain structure. Consequently, the detection volume is entirely filled with cerebellum tissues.

For ${ }^{18} \mathrm{~F}$-FDG studies in the striatum, $73 \%$ of the detection volume was filled with striatal tissues, whereas for ${ }^{11} \mathrm{C}$-Raclopride this proportion is only of $38-50 \%$ depending on the stereotaxic coordinates of implantation. This difference between both isotopes is explained by the limited range of ${ }^{18} \mathrm{~F}$ positrons (the total developed range in the continuous slowing down approximation is of $2.3 \mathrm{~mm}$ for ${ }^{18} \mathrm{~F}$ (Berger et al 1999) compared to that of ${ }^{11} \mathrm{C}$ positrons (3.9 mm developed range). The corresponding maximum distance from emission point to annihilation is about $1.5 \mathrm{~mm}$ for ${ }^{18} \mathrm{~F}$ compared to $2.3 \mathrm{~mm}$ for ${ }^{11} \mathrm{C}$ (Levin and Hoffman 1999, 
Desbrée et al 2004)). For ${ }^{11} \mathrm{C}$-Raclopride studies, non-striatal tissues represent $50 \%$ or more of the detection volume, but their contribution to the overall signal is less than $9 \%$ immediately after the tracer injection and decreases rapidly while ${ }^{11} \mathrm{C}$-Raclopride binds specifically to D2 receptors in striatal tissues. This favorable situation results from the relatively high specificity of ${ }^{11} \mathrm{C}$-Raclopride and also from the large dimensions of striatum. Voxels of the detection volume, which do not belong to the striatum are remote from the probe and consequently, present low local detection efficiencies compared to voxels close to the probe. This situation occurs in microprobe studies, when the probe is implanted in the structure of interest.

The correction factor (1.25) applied to Ginovart et al microprobe data obtained in the rat striatum was not sufficient to make the radioactivity concentration quantification comparable with the ex vivo counting of striatal tissues. One possible explanation is the experimental overestimation of the probe sensitivity during the experimental calibration. Although the theoretical calibration for a $500 \mu \mathrm{m}$ diameter $1 \mathrm{~mm}$ long probe is $0.51 \mathrm{cts} \mathrm{kBq}^{-1} \mathrm{ml}^{-1}$ for ${ }^{11} \mathrm{C}$ tracers, the values reported by Ginovart et al is $0.73 \pm 0.15 \mathrm{cts} \mathrm{kBq}^{-1} \mathrm{ml}^{-1}$. The significant imprecision on the calibration factors measurements $(16.8 \%$ and $20 \%$ relative error for the striatum and cerebellum probe respectively) in their study could further explain the underestimation of the striatal radioactivity using the microprobe data.

To complete the evaluation of the probe quantification, we have also simulated the only experiment carried out so far with the microprobe and ${ }^{15} \mathrm{O}$-water (Weber et al 2003). However, for ${ }^{15} \mathrm{O}$ studies, the detection volume is very large leading to a severe underestimation of the radioactivity concentration. Indeed, the detection volume is filled not only with cortical tissues but also with other brain tissues and largely by air. The $\beta$-microprobe technique use with ${ }^{15} \mathrm{O}$ tracers is limited in terms of spatial resolution and quantification accuracy. ${ }^{15} \mathrm{O}$-water studies present two major disadvantages: the decay of ${ }^{15} \mathrm{O}$ is very fast (half life $=2 \mathrm{~min}$ ), and the maximum energy of the ${ }^{15} \mathrm{O}$ spectrum limits severely the spatial resolution. Therefore, the quantification ability of ${ }^{15} \mathrm{O}$-water with the probe is limited to the measurement of relative changes in cerebral blood flow rather than absolute values.

\subsection{Probe calibration and probe dimensions}

The microprobe calibration procedure consists in immersing the probe scintillating tip in a beaker filled with an aqueous solution of known concentration of radioactivity of ${ }^{18} \mathrm{~F},{ }^{11} \mathrm{C}$ or ${ }^{15} \mathrm{O}$. To ensure accurate measurements, a high concentration is used (typically $20 \mathrm{MBq}$ in $10 \mathrm{ml}$ ) leading to a count rate of several hundreds (typically $400-500$ counts s$^{-1}$ for a $500 \mu \mathrm{m}$ diameter probe with a $1 \mathrm{~mm}$ long scintillating tip), thus limiting statistical noise. The activity and volume of the calibrating solution are measured using precision pipettes and a $4 \pi$ radioactive counter. Attention should be paid to the residual activity in the pipette or cone, which is counted in the same counter and subtracted from the total activity. The Cerenkov signal generated in the water solution by positrons traveling faster than the light speed in water (i.e., positrons with energy superior to $145 \mathrm{keV}$ ) might bias the calibration factor leading to an overestimation of the probe sensitivity. To suppress the Cerenkov signal, we recommend to darken the radioactive calibration solution with India ink, which absorbs most of the Cerenkov light emitted in water. If all this necessary precautions are taken, the evaluation of the probe sensitivity can be realized with a relative error of less than $5 \%$ mainly due to statistical noise. For studies in large brain loci where the detection volume is entirely included within the structure, this value can be used straightforward to derive the absolute local radioactivity concentration. For smaller structures, calculation of the apparent sensitivity as defined in the present study is required. It should be emphasized that the use of the correction factors derived from simulations implies that the geometry of the probe (diameter and length of the 
scintillating tip) in real experiments and in simulation is the same. Therefore, probes used in experiments where correction factors are involved should be carefully characterized under a microscope to determine exactly the length of their sensitive tip.

\subsection{Accuracy of stereotaxic placement}

For relatively large brain structures such as the striatum, the present work demonstrated that even a $800 \mu \mathrm{m}$ error on any coordinates has little effect on the apparent sensitivity value and consequently on quantification. The accuracy of stereotaxic surgery is commonly evaluated by neurophysiologists to $500 \mu \mathrm{m}$ on any coordinates. This value is also given by Paxinos and Watson in the accompanying text to their atlas of the 'Rat Brain in Stereotaxic Coordinates' (Paxinos and Watson 1998). This estimate is highly dependant on several parameters including influence of strain and weight variations, atlases accuracy and experimentalist's skills for implantation in a particular brain locus. The influence of rat strain and weight on stereotaxic accuracy has been a concern for years for neurophysiologists when using brain atlas coordinates to target a brain location. It was shown that 'no substantial stereotaxic error occurs when rats of different sex and strain are chosen provided that the rats are of similar weight to those on which the atlas is based' (Paxinos et al 1985, and table 1 in Paxinos and Watson 1998). The rat brain atlas used in $\beta$-Assistant is based on an average over 100 Wistar rats with a mean weight of $290 \mathrm{~g}$. It is intended to be used accurately with male or female rats with weight ranging from $250 \mathrm{~g}$ to $350 \mathrm{~g}$ (Paxinos et al 1985). Given these limitations and considering a $500 \mu \mathrm{m}$ accuracy of probe placement in any directions, two experimental situations may occur for $\beta$-microprobe studies in rat. First, if the probe is implanted close to the center of a large structure (e.g., striatum and cerebellum in Ginovart et al, Zimmer et al and Millet et al studies), then the effect of placement inaccuracy on quantitation is limited. The comparison of the optimal set of stereotaxic coordinates to those used to monitor ${ }^{11} \mathrm{C}$ Raclopride binding in the rat striatum (Zimmer et al 2002a, Ginovart et al 2004) shows that in both groups the implantation localization was reasonably close to the optimal, and that the imprecision on stereotaxic implantation should not affect reproducibility of measurements. Second, for smaller, irregularly shaped brain structures, or when the probe is implanted at the edge of a large structure, the accurate knowledge of coordinates of implantation is critical for the evaluation of each locus contribution and for a precise subtraction of the beta signal from adjacent tissues. In the realistic experimental situations studied in this report, a $600 \mu \mathrm{m}$ error in any direction leads to very strong variations on the recorded signal. This inaccuracy on quantitation is significant, but does not impair relative measurements such as decrease or increase of tracer binding under pharmacological challenges, for instance. If a more precise quantitation is required, the localization of the actual probe position has to be carried out and to be accounted. There are two validated ways to achieve precise probe localization. $\beta$-microprobe localization with high-resolution anatomical MRI imaging was recently successfully performed (Desbrée et al 2007), and allows in vivo localization of the probe, thus making longitudinal studies possible with chronically implanted probes. In the absence of anatomical MRI imaging facility, classical post-mortem histology should be systematically performed to check the probe placement as done routinely in Neurosciences laboratories for electrophysiology, microdialysis or electrochemical electrodes.

\subsection{Optimization of sensitivity}

Sensitivity has become a major concern for small-animal PET studies because of the obligation to limit the total amount of radio-labeled molecules injected to remain in the 
'tracer dose' situation for neuropharmacological studies (Hume et al 1998). $\quad \beta$-Assistant provides optimization of the probe sensitivity through a choice of the most favorable set of stereotaxic coordinates. So far the optimization is based only on anatomical criteria; however, the choice of stereotaxic coordinates obviously depends also on tracer distribution. We suggest the following methodology to choose the more appropriate stereotaxic coordinates in microprobe experiments. First, a priori knowledge regarding the molecular target (i.e., receptors distribution in the brain structure of interest) should be taken into consideration. Second, on the basis of these data, a set of stereotaxic coordinates is derived from 2D coronal sections of a stereotaxic atlas. Third, $\beta$-Assistant is used to optimize the set of coordinates taking into consideration the $3 \mathrm{D}$ anatomy. Furthermore, for structures with highly heterogeneous binding and irregular shapes a biodistribution matrix for a particular tracer can be obtained from the volumetric reconstruction of autoradiographic data as implemented recently by our colleagues in Orsay (Dubois et al 2007). In that case, prior to in vivo experiments, autoradiography would have to be carried out to obtain the biodistribution matrix to be used in $\beta$-Assistant. For instance, before a longitudinal study that targets a brain structure with heterogeneous binding, the experimentalist performs autoradiography on a group of rats to obtain the tracer biodistribution matrix, and use these data and $\beta$-Assistant to set the optimal implantation coordinates. For future mouse studies, optimization of the detector sensitivity is critical, since the absolute amount of detectable radioactivity is low. To that aim a mouse version of $\beta$-Assistant will be implemented and should prove to be useful for future mouse experiments with $\beta$-microprobes.

\section{Conclusions}

We give in this paper some reference values (detection efficiencies for $511 \mathrm{keV}$ gammas for several organs, detection efficiencies and detection volumes for several probes geometry and isotopes) and tools ( $\beta$-Assistant atlases and $\mathrm{m}$-files will be available on request to the authors) for $\beta$-microprobe users to help them in interpreting their data. Our simulations of realistic experimental schemes have confirmed that the background contribution of $511 \mathrm{keV}$ is negligible for most experiments, and remains minimal even for the most unfavorable detection scheme. Although these results address particular brain experiments in the striatum, they can be generalized to any brain experiment with PET radiotracers, since the calculated detections efficiency for $511 \mathrm{keV}$ gammas from peripheral organs are almost insensitive to probe location. For the positron signals, two experimental situations can be distinguished: (1) the whole detection volume is entirely filled by tissues from the structure of interest; (2) the detection volume covers at least partly several brain loci. In the first case, the local radiotracer concentration is obtained straightforwardly by dividing the recorded count rate by the sensitivity of the system. This implies that the sensitivity is cautiously measured experimentally taking into account the potential experimental sources of inaccuracy: accuracy of the radioactivity concentration of the calibration solution and elimination of the Cerenkov signal in water. In the second case, quantification implies the evaluation of the contribution of each brain structure to the overall signal. To that aim, we have developed a Monte Carlo based method that provides with apparent sensitivity calculations for each brain structure given in the precise probe location and dimensions. The influence of the stereotaxic positioning accuracy was studied for several representative schemes. Although this parameter is not critical for some studies where the probe is implanted in the center of a large structure (e.g., ${ }^{11} \mathrm{C}$-Raclopride binding in the striatum) or positioned just above a large area of cerebral activation (the ${ }^{18}$ F-FDG study of somatosensory activation in the barrel cortex), it is critical for most $\beta$-microprobe experiments. Therefore, precise probe localization should be achieved 
either through anatomical MRI imaging or classical post-mortem histology. Finally, we propose to optimize the stereotaxic coordinates of implantation using a methodology based on a priori knowledge of the distribution of molecular targets and anatomical optimization using $\beta$-Assistant.

\section{Acknowledgments}

The authors thank Christine Walczak for animal handling in the Institut Curie in Orsay (France) and Helio Yoriyaz from the Instituto de Pesquisas Energéticas e Nucleares in Sao Paolo (Brasil), for helpful advice on definition of Monte Carlo voxelized geometry using SCMS. This work was supported by the CNRS/CEA/INSERM program 'Imagerie du Petit Animal'.

\section{References}

Berger M J, Coursey J S and Zucker M A 1999 ESTAR, PSTAR and ASTAR: Computer Programs for Calculating Stopping Power and Range Tables for Electrons, Protons and Helium Ions http://physicsnistgov/Star

Briefmeister J F 2000 MCNP_A General Monte Carlo N Particle Transport Code, Version 4C Los Alamos National Laboratory

Desbrée A, Pain F, Gurden H, Zimmer L, Pinot L, Lanièce P and Mastrippolito R 2004 Combining the radiosensitive $\beta$-microprobe to nuclear magnetic resonance: theoretical approach for in vivo studies in small animals J. Neurosci. Methods 140 47-52

Desbrée A, Rbah L, Langlois J B, Grenier D, Mastrippolito R, Pain F, Pinot L, Lanièce P, Zimmer L and Gurden H 2007 Simultaneous in vivo magnetic resonance imaging and radioactive measurements with the beta-microprobe Eur. J. Nucl. Med. Mol. Imaging 34 1868-72

Dhenain M, Ruffins S W and Jacobs R E 2001 Three-dimensional digital mouse atlas using high-resolution MRI Dev. Biol. 232 458-70

Dubois A et al 2007 Automated three-dimensional analysis of histological and autoradiographic rat brain sections: application to an activation study J. Cereb. Blood Flow Metab. 27 1742-55

Galineau L, Wilson A A, Garcia A, Houle S, Kapur S and Ginovart N 2006 In vivo characterization of the pharmacokinetics and pharmacological properties of [11C]-(+)-PHNO in rats using an intracerebral betasensitive system Synapse 60 172-83

Ginovart N, Sun W, Wilson A A, Houle S and Kapur S 2004 Quantitative validation of an intracerebral $\beta$ sensitive microprobe system to determine in vivo drug-induced receptor occupancy using [11C]raclopride in rats Synapse $\mathbf{5 2} 89-99$

Hoffman E J, Huang S C and Phelps M E 1979 Quantification in positron emission tomography: I. Effects of object size J. Comput. Assist. Tomogr. 3 299-308

Hume S P, Gunn R T and Jones T 1998 Pharmacological constraints associated with positron emission tomoraphic scanning of small laboratory animals Eur. J. Nucl. Med. $25173-6$

Hume S P, Lammertsma A A, Myers R, Rajeswaran S, Bloomfield P M, Ashworth S, Fricker R A, Torres E M, Watson I and Jones T 1996 The potential of high-resolution positron emission tomography to monitor striatal dopaminergic function in rat models of disease J. Neurosci. Methods 67 103-12

Kornblum H 2000 In vivo imaging of neuronal activation and plasticity in the rat brain by high-resolution positron emission tomography (microPET) Nat. Biotechnol. 18 655-60

Kuge Y, Minematsu K, Hasegawa Y, Yamaguchi T, Mori H, Matsuura H, Hashimoto N and Miyake Y 1997 Positron emission tomography for quantitative determination of glucose metabolism in normal and ischemic brains in rats: an insoluble problem by the Harderian glands J. Cereb. Blood Flow Metab. 17 116-20

Levin C S and Hoffman E J 1999 Calculation of positron range and its effect on the fundamental limit of positron emission tomography system spatial resolution Phys. Med. Biol. 44 781-99

Mauger G, Saba W, Hantraye P, Dolle F, Coulon C, Bramoullé Y, Chalon S and Grégoire M C 2005 Multiinjection approach for $\mathrm{D} 2$ receptor binding quantification in living rats using [11C]raclopride and the $\beta$-microprobe: crossvalidation with in vitro binding data J. Cereb. Blood Flow Metab. 25 1517-27

Meikle S R, Eberl S, Fulton R R, Kassiou M and Fulham M J 2000 The influence of tomograph sensitivity on kinetic parameter estimation in positron emission tomography imaging studies of the rat brain $\mathrm{Nucl}$. Med. Biol. 27 617-25 
Millet P, Sallanon M M, Petit J M, Charnay Y, Vallet P, Morel C, Cespuglio R, Magistretti P J and Ibanez V 2004 In vivo measurement of glucose utilization in rats using a $\beta$-microprobe: direct comparison with autoradiography J. Cereb. Blood Flow Metab. 24 1015-24

Pain $\mathrm{F}$ et al 2002b In vivo quantification of localized neuronal activation and inhibition in the rat brain using a dedicated high temporal resolution $\beta$-sensitive microprobe Proc. Natl Acad. Sci. USA 99 10807-12

Pain F, Lanièce P, Mastrippolito R, Charon Y, Comar D, Leviel V, Pujol J F and Valentin L 2000 SIC, an intracerebral rdiosensitive probe for in vivo neuropharmacology investigations in small laboratory animals: theoretical considerations and physical characteristics IEEE Trans. Nucl. Sci. 47 25-32

Pain F, Lanièce P, Mastrippolito R, Charon Y, Comar D, Leviel V, Pujol J F and Valentin L 2002a SIC, an intracerebral radiosensitive probe for in vivo neuropharmacology investigations in small laboratory animals: first prototype design characterization and in vivo evaluation IEEE Trans. Nucl. Sci. 49 822-6

Pain F, Lanièce P, Mastrippolito R, Hantraye P, Gervais P and Besret L 2004 Arterial input function measurement without blood sampling using a $\beta$-microprobe in rats J. Nucl. Med. 45 1577-82

Paxinos G and Watson C 1998 The Rat Brain in Stereotaxic Coordinates 4th edn (San Diego: Academic)

Paxinos G, Watson C, Pennissi M and Topple A 1985 Bregma, lambda and the interaural midpoint in stereotaxic surgery with rats of different sex, strain and weight J. Neurosci. Methods 13 139-43

Petersen C C 2007 The functional organization of the barrel cortex Neuron 56 339-55

Rbah L, Leviel V and Zimmer L 2003 Displacement of the PET ligand ${ }^{18}$ F-MPPF by the electrically evoked serotonin release in the rat hippocampus Synapse $49239-45$

Riad M, Zimmer L, Rbah L, Watkins K C, Hamon M, Descarries L and Leviel V 2004 Acute treatment with the antidepressant fluoxetine internalizes 5-HT1A autoreceptors reduces the in vivo binding of the PET radioligand $\left[{ }^{18} \mathrm{~F}\right] \mathrm{MPPF}$ in the nucleus raphe dorsalis of rat J. Neurosci. 24 5420-6

Slifstein M, Hwang D, Martinez D, Ekelund J, Huang Y, Hackett E, Abi-Dargham A and Laruelle M 2006 Biodistribution and radiation dosimetry of the dopamine D2 Ligand 11C-Raclopride determined from human whole-body PET J. Nucl. Med. 47 313-9

van Waarde A, Cobben D C, Suurmeijer A J, Maas B, Vaalburg W, de Vries E F, Jager P L, Hoekstra H J and Elsinga P H 2004 Selectivity of ${ }^{18}$ F-FLT and ${ }^{18}$ F-FDG for differentiating tumor from inflammation in a rodent model J. Nucl. Med. $\mathbf{4 5}$ 695-700

Vasdev N, Natesan S, Galineau L, Garcia A, Stableford W T, McCormick P, Seeman P, Houle S and Wilson A A 2006 Radiosynthesis, ex vivo and in vivo evaluation of [11C]-preclamol as a partial dopamine D2 agonist radioligand for positron emission tomography Synapse. $60314-8$

Weber B, Spath N, Wyss M, Wild D, Burger C, Stanley R and Buck A 2003 Quantitative cerebral blood flow measurements in the rat using a b-probe and $\mathrm{H}_{2}{ }^{15} \mathrm{O}$ J. Cereb. Blood Flow Metab. 23 1455-60

Yoriyaz H, Stabin M G and dos Santos A 2001 Monte Carlo MCNP-4B-based absorbed dose distribution estimates for patient specific dosimetry J. Nucl. Med. 42 662-9

Zimmer L, Hassoun W, Pain F, Bonnefoi F, Lanièce P, Mastrippolito R, Pinot L, Pujol J F and Leviel V 2002a SIC, an intracerebral $\beta$ sensitive probe for radiopharmacology investigations in small laboratory animals: binding studies with [11C]-Raclopride J. Nucl. Med. 43 227-33

Zimmer L, Pain F, Mauger G, Plenevaux A, Le Bars D, Mastrippolito R, Pujol J F, Renaud B and Lanièce P 2002b The potential of the b-microprobe, an intracerebral radiosensitive probe, to monitor the $\left[{ }^{18} \mathrm{~F}\right]$-MPPF binding in the rat dorsal raphe nucleus Eur. J. Nucl. Med. 29 1237-47

Zimmer L, Riad M, Rbah L, Belkacem-Kahlouli A, Le Bars D, Renaud B, Descarries L, Watkins K C, Hamon M and Leviel V 2004 Toward brain imaging of serotonin 5-HT1A autoreceptor internalization Neuroimage 22 1421-6 